\title{
Research on the Present Situation of Contemporary College Students' Idol worship and Countermeasures
}

\author{
Gu Hanke \\ China Jiliang University \\ Hangzhou, 310018 China
}

\begin{abstract}
At present, idol worship is a relatively common social phenomenon in college students. It not only affects the study and life of college students, but also affects the construction of college students' ideological and moral qualities and value ideals. In order to play the leading role of the icon of the new era idol, based on the study of the phenomenon of idol worship of college students, this paper explores the value of ideological education inherent in idol worship, and proposes practical guidance measures from four aspects: society, colleges, families and individuals.
\end{abstract}

Keywords-college students; idol worship; ideological education; model lead

\section{INTRODUCTION}

As a special social and cultural phenomenon, idol worship plays an important role in the ideological and moral growth of college students.Thetraditional "moral model" image is gradually replaced by "idol" because it is difficult to integrate with the actual life of college students. The leading role of the model is gradually weakened.This thesis aims to study the idol worship phenomenon of college students, explore the ideological education value of idol worship, and put forward practical and feasible guiding measures to play the role of the icon of the new era idol.

\section{CHARACTERISTICS OF CONTEMPORARY COLLEGE STUDENTS' IDOL WORSHIP}

\section{A. Contemporaneity of idol worship}

Model education is not only an important means of ideological and political education, but also an important means of governance for our party. Our party has set different role models according to the ruling needs of historical missions in different periods.During the period from the 1950s to the 1980s, Mao Zedong established such battlefield heroes as Bethune, Liu Hulan, Lei Feng, Wang Jinxi and other great works and inscriptions such as "Commemorating Bethune", "Serving the People", and "Learning to Comrade Lei Feng". The typical examples established during this period are highly publicized by the government at all levels, with obvious political orientation, fully embodying the organic combination of the national spirit and the spirit of the times, the dialectical unity of the principle of party spirit and the principle of people, personal values and socialvalues.Since the mid-1980s, with the development of popular culture, "tri -star" represented by "singers, movie stars, sports stars" has begun to occupy the youth market. During this period, the Chinese women's volleyball team "not afraid of strong enemies, not giving up" emerged, and also discovered the actors who carried out
Chinese Kung Fu as representative of Jet Li. The essence of the formation of "tri -star" is that the social learning and attachment with the core of the characters is the process of the idealization, absoluteization and romanticization of the idol occupation.After entering the 21 st century, with the application of new media means such as Weibo, WeChat, and YouTube, everyone can have their own display platform and enter the era of "pan-idol". Most of these idols were born in grassroots, and their way of debuting included spreading through the Internet through the display of personal images and individual performances, or the media's packaging of idols, or the formation of different selection methods such as cultivation and practice students. Become a new generation of idols. Under the media rendering, "Folk star" has become not only a youth symbol of "anti-elite", but also from "star idol" to "Folk star" is a fashion trend of "anti-star". Class idols, while tracking and sharing their dynamics, also express the desire to shape themselves into the next idol through the Internet.

\section{B. Pluralism of idol worship}

Data network based on the 2015 youth popular culture research report ", "idol" of teen choice as the top three, respectively is entertainment stars, sports stars, professionals, accounted for $44.9 \%, 21.7 \%$ and $13.6 \%$ respectively, and also a business celebrities, virtual characters, political leaders, such as Internet star choice, is to fill in the "other" idol also appeared in the classmate, boyfriend, brother, boss, these answers. According to the report, non-traditional "idols" gradually occupy one place in the choice of young people, showing the diversity and autonomy of young people's choice of "idols". The current "idol" has jumped out of the "media propaganda", and the mode of choosing from it is evolving to the direction of teenagers' independent will choice.

The reasons are as follows: firstly, influenced by globalization, today's society gradually increases tolerance to various cultures and allows the existence and development of individuality, which is the external condition of idol diversification. Secondly, the individual differences of college students in value orientation, psychological needs and other aspects will affect the selection of idol worship objects to some extent. Finally, with the rapid development of the Internet, college students have more opportunities to contact with different social cultures in the world. In addition, with the development of we-media, a large number of "web celebrity" and "civilian idols" have emerged, making the selection of college students' idols more diversified and simple. For example, nowadays, college students' idols are distributed in various professions such as entertainment stars, sports athletes and entrepreneurs, as well as "web celebrity", which has 
emerged on weibo, douyin and other apps, and innocent contestants in the cultivation programs (such as creation 101) that generate idols independently.

\section{Diversity of idol worship}

In the early days, the ways to express worship to idols included expressing admiration, appreciation and other emotional expressions, imitating the dressing and behavior of idols, or buying albums and movies supporting idols. However, with the development of new online media, college students have changed from passive acceptance to active producer. The Internet has visualized and quantified the power of fans, which is often reflected by clicks, downloads and popular searches, such as fans' support, fans' public welfare, fans' public relations, fans' advertisements and fans' text propaganda. Unlike in the past, when they simply shouted for idols, contemporary college students give full play to their personal abilities and strengths to carry out different forms of online and offline activities through social platforms to help the development of idols. Due to its huge base, fans can deeply participate in the shaping and development of idols. They will give strong opinions on the development path, design and shaping of idols, film and television resources, and even clothing collocation. It not only has a profound impact on the entertainment market and social atmosphere, but also affects the choice of the market to some extent.

\section{THE PROBLEMS EXISTING IN IDOL WORSHIP OF CONTEMPORARY COLLEGE STUDENTS}

\section{A. Idol cognitive bias exists}

Nowadays college students' idol worship is mostly influenced by mass media. The formation of new era idols is mostly "packaged" by commercial companies, with specific character Settings presented in front of us, allowing us to temporarily escape from daily life. Therefore, the idol worship process of college students is full of highly idealized and romanticized fantasies, which overlap the screen image with the real image, ideal cognition and real situation, blind worship and pursuit of idols, lose the comprehensive cognition of idols and evolve into irrational and non-objective idol worship. For example, the "scholar-lord" actor zhai tianlin was recently exposed for falsifying his academic misconduct papers, which caused many fans to collapse their long-held cognition of "scholar-lord".

\section{B. Consumer idol worship stands out}

Idols can be divided into consumption idols and production idols. Consumer idol to entertainment, sports, e-sports circle and other influential flow of stars, and production idol to business, politics, science and other leaders can bring great value to society. Compared with production idols, consumption idols have higher exposure, attention and more luxurious and delicate life that college students desire. College students realize that the real life and ideal life cannot be realized, so they can project some ideal and desire of themselves onto the idol, which can not only obtain substitute sexual satisfaction by projecting onto the idol, but also obtain another form of self-realization by focusing on and chasing consumption idol.

\section{Idol worship floats on the surface}

Idol worship can be divided into surface worship and internalization worship according to different levels and contents of worship. The former is to appreciate the outward features such as appearance, dress and temperament, while the latter is to recognize and worship the intrinsic character and values. Theidol worship of contemporary college students is superficial and lacks in deep exploration. First of all, college students are more interested in the idol's outward appearance and gossip news, and seldom take the initiative to understand their real life experience and personal achievements. Secondly, in order to gain eyeballs and click-through rate, the network media mainly reports the entertainment news and gossip of idols, lacking the attention to the personality charm and inner character of idols.

\section{Internet violence derived from idol worship}

For college students' idol worship, the self-centered state of college students is excessively inflated, which will magnify the degree of attention and emotional experience and show emotional and excessive attachment characteristics. When faced with doubts and negative news about their idols, college students are unable to properly view their idols' shortcomings and external evaluation. Thus, blind and irrational behaviors such as group control of comments, rumor whistleblowers and capital manipulation of public opinions occur. For example, when hip-hop contestant PGone was reported for smoking drugs and insulting women and other facts, he should be subject to public supervision and examination by relevant authorities. However, there are still a large number of fans organizing online abuse wars, human flesh whistleblowers, spreading rumors and seriously injuring innocent passers-by, and other serious online violence behaviors, trying to explain for the idol.

\section{GUIDING COUNTERMEASURES OF RATIONAL IDOL WORSHIP FOR COLLEGE STUDENTS}

\section{A. Strengthen supervision and give correct guidance to public}

Nowadays, the prosperity of idol industry cannot be separated from the rendering and promotion of mass media. Driven by the market economy, a large number of people in online media obtain benefits by fabricating facts and creating topics. Some college students with weak cognition are either deeply in idol worship or unconsciously produce network violence under the guidance of public opinion in the entertainment gossip which is true or false. Mass media is an important window for cultural propaganda, shouldering important social responsibilities. Media people should understand that their idol news and comments have a profound impact on college students. On the one hand, mass media should strengthen internal self-examination and take measures against fake and vulgar news to purify the cyberspace. On the other hand, media reports on idols should be fair and objective. They should not only pay attention to and report the positive idols who are dedicated and enthusiastic about public welfare, but also timely criticize the idols whose behaviors are not conducive to promoting the positive social energy, consciously promote the social theme, and guide the rational idol worship of college students. 


\section{B. Remodel spiritual idols and exert the power of role models}

Idol worship has become an important part of college students' life and an important process in their self-seeking process. So educators should first when carrying out ideological and political education work to correct understanding of idol worship psychology, deeply understand the causes of college students' idol worship, communicate with each other in a fair manner, and guide students to correct recognition of idols, and inspire college students thinking about the meaning of idol worship, realize the ideal and the reality gap, completed the construction of self-awareness. Secondly, colleges and universities should pay attention to the effect of idol worship and use the role model to carry out ideological and political education. Including in the daily study combined with the example of the idol, through the propaganda of the idol's own spiritual connotation and behind the efforts, in a more resonant way to play the idol's "role model", so as to through the idol's success from my encouragement.

\section{Respect children's choice, pay attention to family education and guidance}

Family education plays an imperceptible role in guiding children, and parents' education plays an important role in establishing rational idol worship concept for children. With the development of The Times, the choice of idols is more diversified and abundant than that of parents' generation, which inevitably leads to differences and generation gap between children and their idol worship. Therefore, first of all, parents should face idol worship with a correct attitude, actively understand their children's idol worship objects, respect their children's choice, and pay attention to their emotional needs. Secondly, through both sides can accept the way, guide the children to follow the stars rationally in an appropriate way, at the same time, explore the shining points of the idols, encourage the children to learn the good qualities of the idols, so as to achieve the guiding role of family education.

\section{Strengthen self-education and improve cognition and judgment ability}

Self-education is the quickest and most effective way to improve one's ability and accomplishment. To strengthen the self-education ability of college students, we should start from the three aspects of self-cognition, self-supervision and self-evaluation. First of all, college students should have a correct understanding of themselves, understand their strengths, and be able to pinpoint their shortcomings. Treat their own advantages and disadvantages dialectically, change the one-sided and naive cognition of idols, and evaluate their idol worship behavior rationally. Secondly, college students should always reflect on their worship behavior and strengthen self-supervision and restraint. In the face of the comments related to idols on the Internet, we should have an objective and comprehensive understanding, do not believe rumors or spread rumors, restrain our excessive idol worship through self-discipline and self-control, and correct ourselves in time. Finally, college students should have independent ability of identification and evaluation. In the face of public platforms, especially on the Internet to hold their own views, can firm their own position, not be pulled by the speech and blindly pursue and worship.

\section{CONCLUSION}

With the development of Internet and new media technology, idol worship has become a unique cultural and psychological phenomenon among college students, and the value of ideological and political education should be fully explored. Therefore, we should fully recognize the opportunities and challenges under today's idol worship. On the one hand, we should guide college students to look at idols correctly, explore the moral value of idol worship, turn idols into role models, and perfectly combine "idol worship" with "model guidance". In view of the current problems of idol worship, it still needs the joint efforts of the society, universities, families and individuals to strengthen the ideological and political guidance of idol worship for college students.

\section{REFERENCES}

[1] He xiaozhong. Idol subculture and youth model education [M]. Nanchang: jiangxi people's publishing house, 2007:5.

[2] Yue xiaodong, yan fei. A series review of youth idol worship (part three) -- the intergenerational difference of idol worship [J]. Youth studies,2007(05):1-8.

[3] Yue xiaodong. On idol-model education [J]. Journal of Chinese education,2004(09):21-24+62

[4] Yue xiaodong, yan fei. Research on the psychological mechanism of youth idol worship [J]. Chinese moral education,2006(12):11-16.

[5] Yan ke, song zhimin. Mao zedong model education: standards, methods and enlightenment -- from "remembering Bethune" to "learning from comrade lei feng" [J]. Journal of xiangtan university (philosophy and social science edition), 2016,40(03):5-9.

[6] Zhang yanan, Chen chunyan. Research on the rational worship strategies of contemporary college students' idols [J]. Journal of lanzhou institute of education, 2008,34(09):76-78. 